\title{
DESIGN SINGLE AND DUAL BAND STOP FILTER BY USING SPURLINE STRUCTURE
}

\author{
Zainab Alfrgani \\ Microelectronics Research \\ Laboratories, Department of \\ Electrical and Computer \\ Engineering \\ Bright star University
}

\author{
Hassan Aldeeb \\ Microelectronics Research \\ Laboratories, Department of \\ Electrical and Computer \\ Engineering \\ Misurata University \\ University of Colorado, \\ Colorado Spring, USA
}

\author{
Thottam Kalkur \\ Microelectronics Research \\ Laboratories, Department of \\ Electrical and Computer \\ Engineering \\ University of Colorado, \\ Colorado Spring, USA
}

\begin{abstract}
In this paper, we are proposing a design of a spur line single and dual band bandstop filter. We designed, fabricated and characterized spurline filters in two notch frequencies, one at $3.25 \mathrm{GHz}$ and the other at $5.25 \mathrm{GHz}$. The designed filters simulated using Keysight Technologies ADS software and fabricated on FR-4 substrates shows $S_{11}$ of $1 \mathrm{~dB}$ and $S_{21}$ of $20 \mathrm{~dB}$ at notch frequency $3.165 \mathrm{GHz}$ and $S_{11}$ of $2 \mathrm{~dB}$ and $S_{21}$ of $21 \mathrm{~dB}$ at notch frequency $4.98 \mathrm{GHz}$. These two spurlines were combined to obtain dual band band stop filter resulting in $S_{11}$ of $2 \mathrm{~dB}$ and $S_{21}$ of $25 \mathrm{~dB}$ at notch frequency $3.038 \mathrm{GHz}$ and $S_{11}$ of $3 \mathrm{db}$ and $S_{21}$ of $26 \mathrm{~dB}$ at notch frequency $5.2 \mathrm{GHz}$.
\end{abstract}

Keywords - BandStop, Filters, Dual BandStop, ADS, Spurline.

\section{INTRODUCTION}

Band stop filters are used to filter out unwanted signals at certain frequencies in radio frequency communication systems (Saxena et al., 2009) Different approaches are proposed to design band stop filters. In the first approach, a resonator is placed in parallel with main transmission line to tap energy from the main transmission line at resonance frequency (Huang et al. and Aldeeb et al., 2009,2013). In the second approach, open stubs are used to tap energy from the transmission line (Young et al. and Haiwen et al., 2008,2007). In the third approach defected ground structures are used but they are not recommended for practical applications because of packaging issues (Somdotta et al., 2013).
Spurline filters are becoming important for the design of band stop filters because of their compactness and reduced radiation loss and relatively simple structure. Dual band bandstop filters are becoming important in reducing spurious signals in multiband systems. Variety of configurations have been proposed to implement spur-line based dual band bandstop filters. Wang et. al. (2012) proposed a dual spurlines structure to implement a tunable dual band bandstop filter. Parmar et al. (2015) fabricated a dual band filter with spurline with double spurline filter at $\mathrm{S}$ band. In this paper we are proposing a simple split spurline structure to implement a single and dual band bandstop filter.

\section{THEORY AND DESIGN EQUATION OF BAND STOP FILTER BY USING SPURLINE}

Figure (1a) shows the basic structure of a spurline (Nguyen et al., 1983). which works as a bandstop notch filter. Length $(l)$ of the spur line sections is constituted of two parts, length $a$ and gap $g$, $l=a+g$ as shown in Fig1(a). Fig.1b shows the equivalent circuit of the spurline (Bates, 1977).

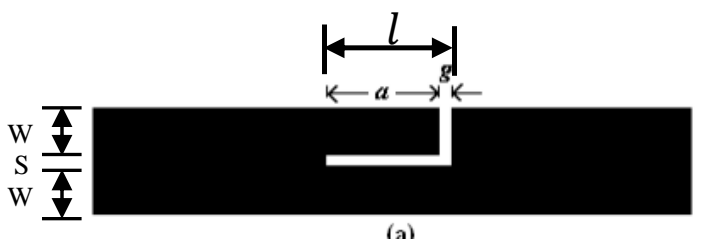

(a) 


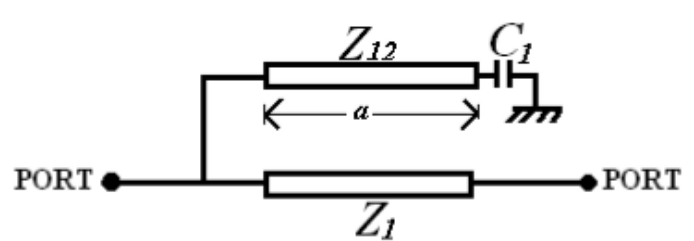

(b)

Figure 1. (a) Spurline schematic. (b) Equivalent circuit of spur line.

The proposed bandstop filter, where the coupled line section were also designed according to the physical length $l$, have two impedances: an open circuit transmission line stub characteristics impedance $Z_{1}$ and a length of line of characteristic impedance $Z_{12}$, were given by Mandal et al. (2008).

$$
\begin{gathered}
Z_{1}=\frac{Z_{o e}}{Z_{o o}}\left(\frac{Z_{o e}+Z_{o o}}{2}\right) \\
Z_{12}=\frac{Z_{o e}+Z_{o o}}{2}
\end{gathered}
$$

Where $Z_{o e}$ and $Z_{o o}$ are even mode and odd mode( 2$)$ characteristic impedances respectively. $a$ is the spurline length which represented by Bates (1977).

$$
a=\frac{C}{f_{0} \sqrt{K_{e f f_{0}}}}-\Delta l
$$

Where:

$\mathrm{C}$ is velocity of light,

$f_{0}$ is operating frequency center,

$K_{\text {effo }}$ is odd mode effective dielectric constant,

$\Delta l$ is effective length extension due to gap $g$,

The length of each spurline is chosen to be $\lambda_{g} / 4$, long in order to create odd mode excitation where $\lambda_{g}$ is the guided wavelength of the microstrip line at the center frequency of operation. The length of spurline and the gap can be used to determine the center frequency.

The phase velocity $\mathrm{V}$ is given by equation (4), which decreases since the spurline improves the effective capacitance of a microstrip line by Benedek et al. (1972):

$$
V=\frac{C}{\sqrt{K_{\text {effe }}}}
$$

And from Mandal et al. (2008)

$$
\Delta l=C_{o d d} \times V_{p o} \times Z_{o o}
$$

From Fig.2, equivalent circuit of microstrip gap capacitance is calculated by Benedek et al. (1972):

$$
\begin{aligned}
& C_{1}=C_{\text {even }} / 2 \\
& C_{12}=\left[C_{\text {odd }}-C_{1}\right] / 2 \\
& \therefore C_{1}+2 C_{12}=C_{\text {odd }} \approx C_{\text {end }}
\end{aligned}
$$

The length of the spur line is affected by the end capacitance, which means controlling the spur line resonators' operation.

In this study, two filters with only one stop band were designed at notch frequencies $3.25 \mathrm{GHz}$, and $5.25 \mathrm{GHz}$ respectively were designed by using ADS Software. The filter layout was down loaded to LPKF machine and the patterns were formed on FR-4 substrate.

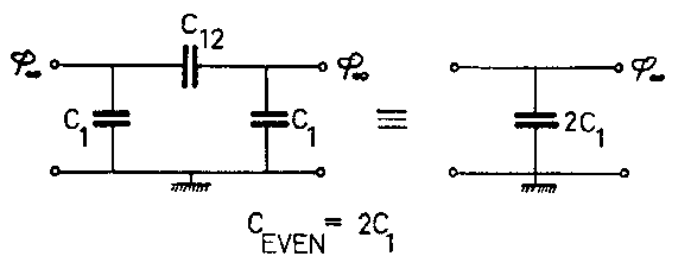

(a)

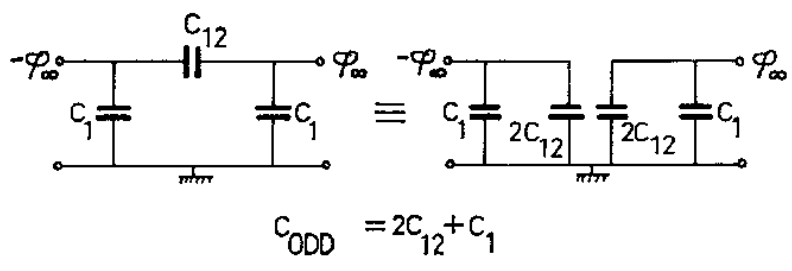

(b)

Figure 2. (a) The even mode equivalent circuit for the gap capacitance.

(b) The odd equivalent circuit.

\section{DESIGN OF BAND STOP FILTER}

\section{A. Design Single BSF at 3.25GHz:}

The circuit designed using ADS software is shown in Fig. (3). The response of this filter can be evaluated by simulating $S_{11}$ and $S_{12}$ as shown in Fig. (4 a). The simulated $S_{11}$ was less than $-0.5 \mathrm{~dB}$ and $\mathrm{S}_{21}$ was $-45 \mathrm{~dB}$ at notch frequency of $3.27 \mathrm{GHz}$. The filter layout was down loaded to LPKF rapid prototype machine to fabricate the filter on FR-4 substrate. SMA connectors were soldered to the input and output and the filters were characterized for $S_{11}$ and $S_{21}$ using 
Agilent network analyzers. Fig. 4b shows the measured response of the filter. The measured $\mathrm{S}_{11}$ was about $-1 \mathrm{~dB}$ and $\mathrm{S}_{21}$ was $-20 \mathrm{~dB}$ at notch frequency $3.165 \mathrm{GHz}$.

Figure 3. Single band stop filter with $3.25 \mathrm{GHz}$

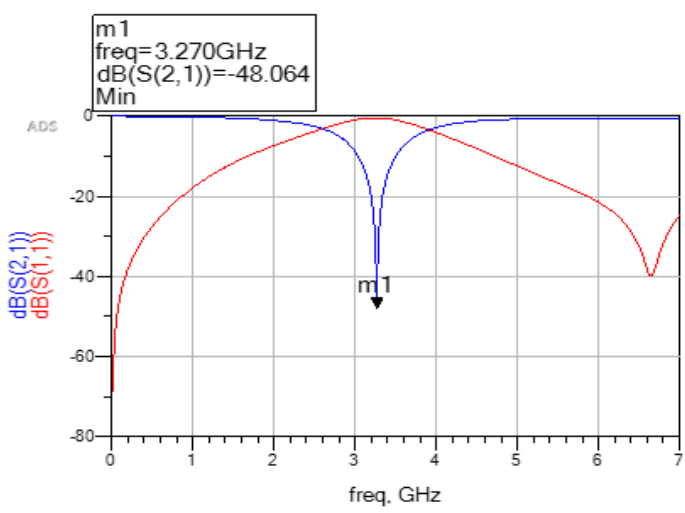

Simulated Result of BST

(a)

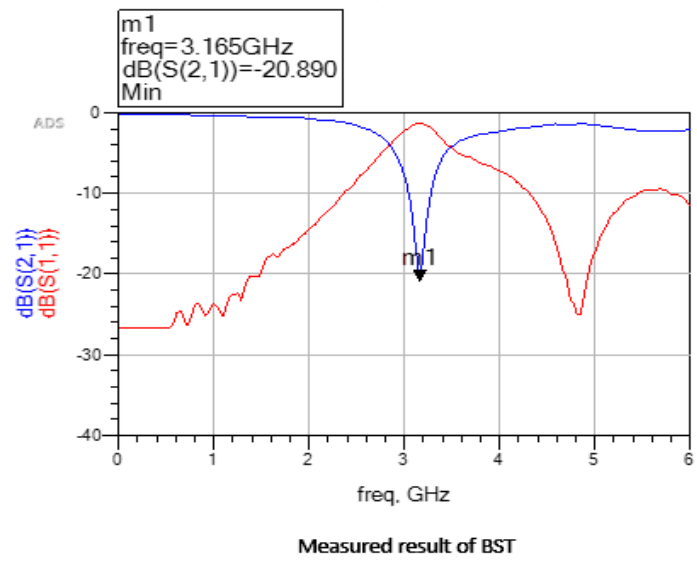

(b)

Figure 4. The simulated and the measured results for single BSF with $3.25 \mathrm{GHz}$.

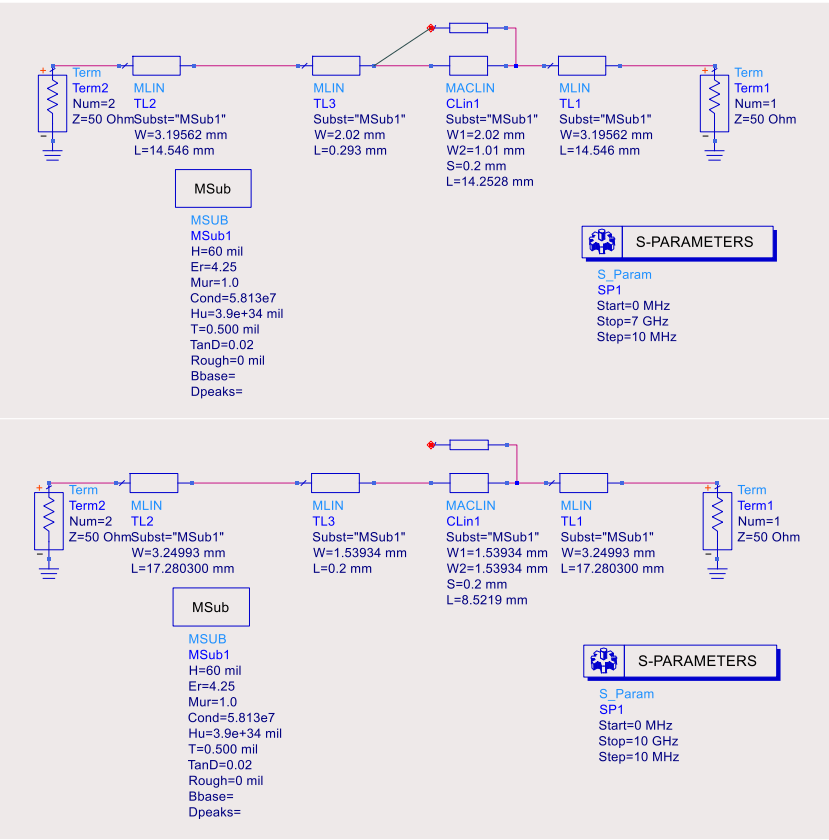

Figure 5. Single band stop filter with $5.25 \mathrm{GHz}$

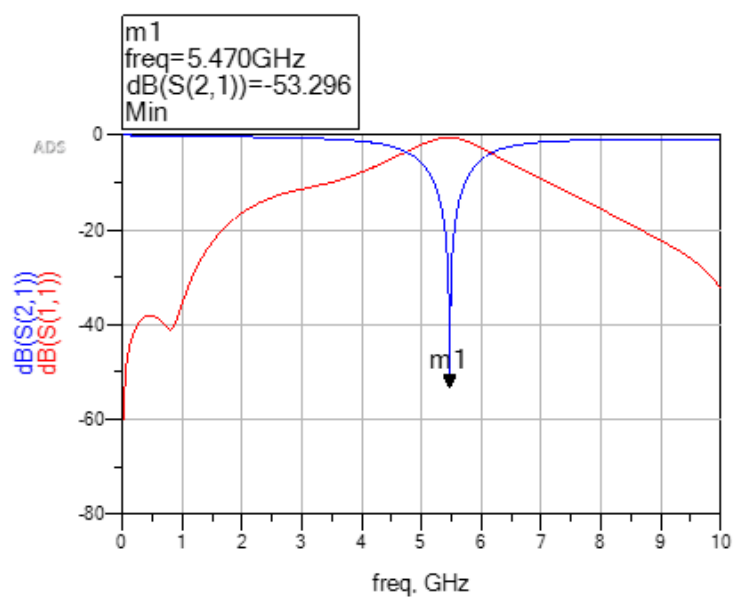

Simulated Result of BST

(a)

\section{B. Design BSF at 5.25GHz:}

Using ADS Software, a single band bandstop filter was designed with higher notch frequency at 5.25 $\mathrm{GHz}$ as shown in Fig. 5. Figure 6a shows the simulated response of the filter. The variation $S_{11}$ with frequency shows that at the notch frequency of $5.47 \mathrm{GHz}$, the $S_{11}$ is about $-0.5 \mathrm{~dB}$ and the $\mathrm{S}_{21}$ is about $-53 \mathrm{~dB}$. Fig. $6 \mathrm{~b}$ shows the measured response of the filter with $S_{11}$ at notch frequency is about $-2 \mathrm{~dB}$ and $\mathrm{S}_{21}$ about $-21 \mathrm{~dB}$. 


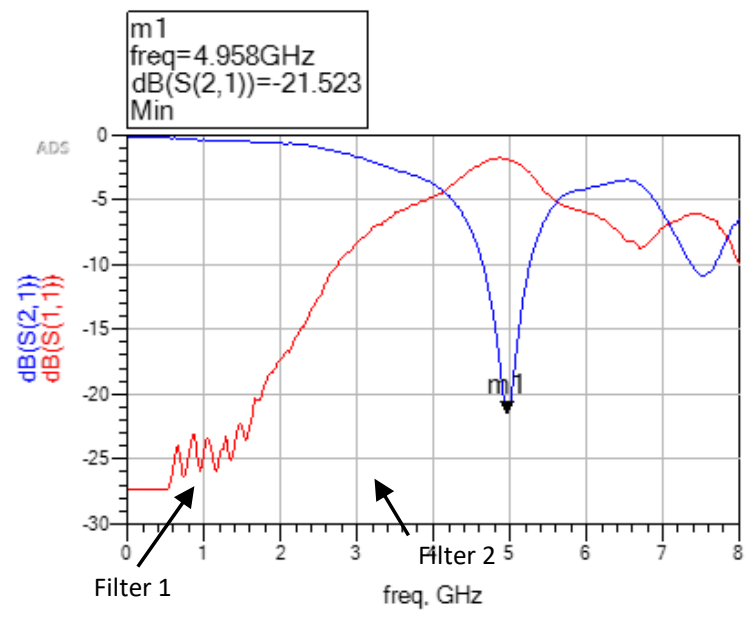

Measured result of BST

(b)

Figure 6. The simulated and the measured results for single band stop filter with $5.25 \mathrm{GHz}$.

\section{DESIGN OF DUAL BAND BSF AT 3.25GHZ AND 5.50 GHZ}

Figure 7 shows the layout of the proposed dual band bandstop filter designed using ADS, where the spur lengths are calculated using equation (3).

The first spurline was designed for the first notch at the lowest frequency $3.25 \mathrm{GHz}$, and the second spurline was designed at a notch frequency of $5.48 \mathrm{GHz}$. Fig. 8 shows the simulation results of the dual band band stop filter. Variation of $S_{11}$ with frequency shows that at the first notch frequency of $3.270 \mathrm{GHz}, \mathrm{S}_{11}$ is about $-0.5 \mathrm{~dB}$ and at the second notch frequency of $5.480 \mathrm{GHz}, \mathrm{S}_{11}$ is about $1 \mathrm{~dB}$. Fig. 9 shows the photograph of filter fabricated with LPKF prototyping machine. Fig 10 shows measured results for the fabricated circuit for dual band band stop filter with notch frequency at $3.048 \mathrm{GHz}$ and $5.169 \mathrm{GHz}$. The measured $S_{11}$ at the first notch frequency is about $-1.5 \mathrm{~dB}$ and at the second notch frequency is about $-2.5 \mathrm{~dB}$. The measured $\mathrm{S}_{21}$ at the first notch frequency is $-25 \mathrm{~dB}$ and at the second notch frequency is about $-26 \mathrm{~dB}$.

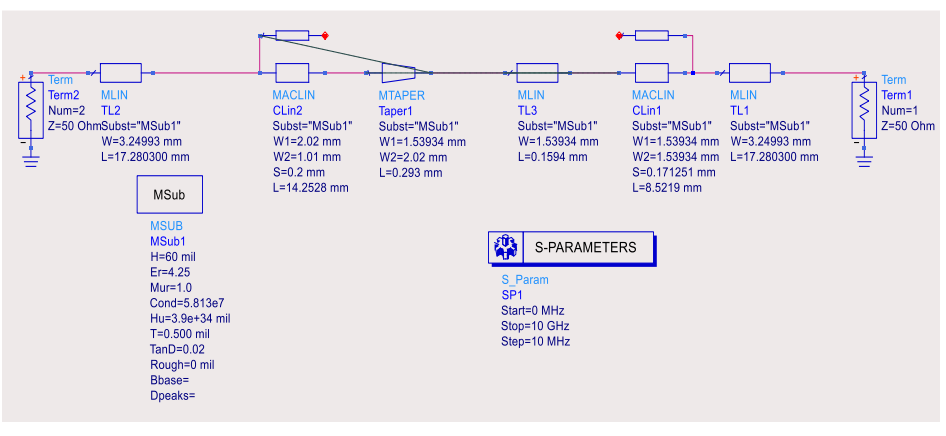

Figure 7 Dual band stop filter circuit used in ADS simulation

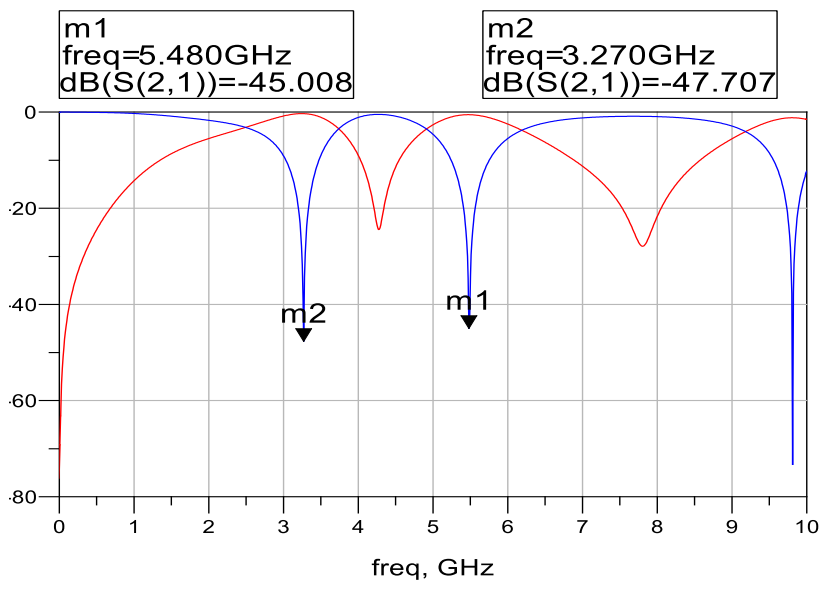

Figure 8. The simulated result by using ADS.

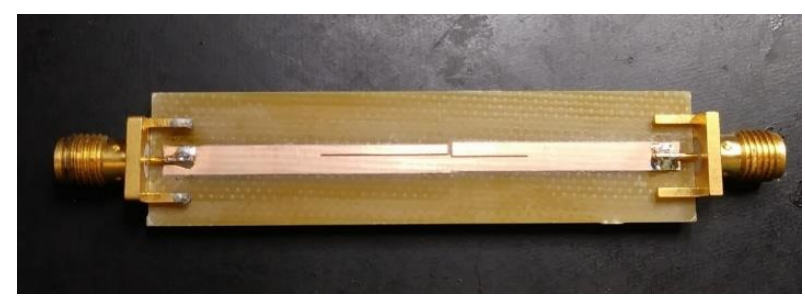

Figure 9. Prototype Circuit for Dual band stop filters at 3.25 and $5.5 \mathrm{GHz}$

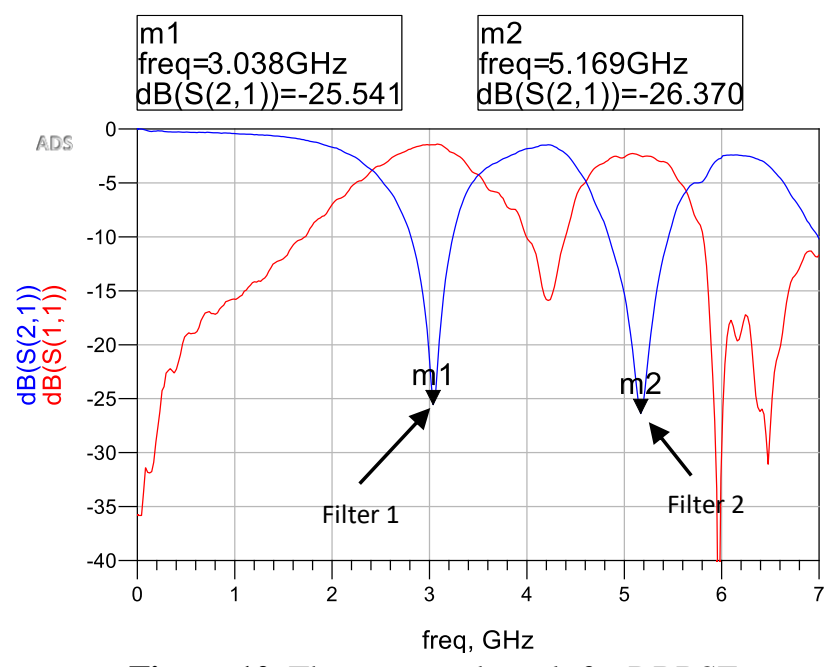

Figure 10. The measured result for DBBSF

\section{CONCLUSION}

In this paper, we used a simple structure to design spurline single and dual band bandstop filters. 


\section{International Journal of Engineering Applied Sciences and Technology, 2019 Vol. 4, Issue 6, ISSN No. 2455-2143, Pages 48-52 \\ Published Online October 2019 in IJEAST (http://www.ijeast.com)}

Two single notch band stop filters at different notch frequencies were designed, simulated fabricated and characterized. Finally, these two filters were combined to fabricate spurline based dual band band stop filters. The fabricated filters notch frequencies are close to design frequency but the $S_{21}$ at notch frequencies is higher than simulated results. This is attributed to LPKF machine tolerances.

\section{REFERENCES}

[1] S. Saxena, S. Porwal, K. Soni, P. Chhawchharia and S. K. Koul. (2009). Novel tunable bandstop filter using E-shaped dual mode resonator. 2009 IEEE International Conference on Microwaves, Communications, Antennas and Electronics Systems, (pp. 1-5).

[2] J. -M. Huang, F. Zhu and Z. L. Deng. (2009). A Novel Design o Tunable Band-Stop Filter Using MEMS Technology. 5th International Conference on Wireless Communications, Networking and Mobile Computing, Beijing, 2009, (pp. 1-3).

[3] Aldeeb, H., and T.S. Kalkur. (2013). Tunable Coplanar wave guide band stop filters. Integrated Ferroelectrics. Vol. 141. Issue 1, (pp. 105-111).

[4] Young-Hoon Chun, Jia-Sheng Hong, Peng Bao, Jackson T.J., Lancaster M.J. (2008). BST varactor tuned bandstop filter with slotted ground structure. IEEE MTT-S International Microwave Symposium Digest, Atlanta, GA, USA, 2008, (pp. 1115-1118).

[5] Haiwen Liu, Reinhard H. Knoechel and Klaus F.Schuenemann. (Oct. 2007). Miniaturized bandstop filter using meander spurline and capacitively loaded stubs. ETRI Journal, Vol.29, no.5, (pp.614-617).
[6] Somdotta Roy Choudhury, Susanta Kr. Parui, Santanu Das. (Oct. 2013). Design of a Compact Wideband Log Periodic Spur Line Bandstop Filter. International Journal of Engineering and Advanced Technology (IJEAT) ISSN: 2249 - 8958, Volume3, Issue-1, (pp.5-13).

[7] Yan-Yi Wang, Feng Wei, Bei Liu, Xiao-Wei Shi. (2012). A tunable Band stop filter using spurlines. International Conference on Microwave and Millimeter Wave Technology (ICMMT), Vol.1, (pp.1-4).

[8] C. Parmar, and MS. Z. Dobariya. (May 2015). Comparison of Microstrip Open Stub Double Spurline BandStop Filter with Double Spurline Filter at $\mathrm{S}$ Band. International Journal of Innovative Research in Technology (IJIRT), Vol 1, Issue 12, (pp. 1280-1288).

[9] C. Nguyen and C. Hsieh. (1983). Millimeter Wave Printed Circuit Spurline Filters. 1983 IEEE MTTS International Microwave Symposium Digest, Boston, MA, USA, (pp. 98-100).

[10] R. N. Bates. (1977). Design of Microstrip Spurline Band-Stop Filters. IEE Journal on Microwaves, Optics and Acoustics, Vol. 1, (pp. 209-214).

[11] M.K Mandal, K. Divyabramham and S. Sanyal. (Oct. 2008). Compact, Wideband Bandstop Filters with Sharp Rejection Characteristics. IEEE Microwave and Wireless Components Letters, Vol. 18, No. 10, (pp. 665-667).

[12] P. Benedek and P. Silvester. (Nov. 1972). Equivalent capacitances for microstrip gaps and steps. IEEE Transactions on Microwave Theory and Techniques, Vol. 20, No. 11, (pp. 729-733). 